CASE STUDY

\title{
Students as Partners in Action: Evaluating a University-Wide Initiative
}

\author{
${ }^{*}$ Leanne Coombe ${ }^{a}$, Jasmine Huang ${ }^{b}$, Stuart Russell ${ }^{b}$, Karen Sheppard ${ }^{b}$, and Hassan Khosravi ${ }^{b}$ \\ a Faculty of Medicine, The University of Queensland, Herston, Australia \\ bInstitute for Teaching and Learning Innovation, The University of Queensland, St Lucia, \\ Australia
}

Contact: l.coombe@uq.edu.au

\begin{abstract}
This case study was designed as one of many pilot projects to inform the scaling-up of Students as Partners (SaP) as a whole-of-institution strategy to enhance the student learning experience. It sought to evaluate the other pilots in order to understand the phenomena of partnerships and how students and staff perceive the experience of working in partnership. It also sought to explore the extent of benefits and challenges experienced by staff and students throughout the process and identify potential implications for future implementation.
\end{abstract}

\section{KEYWORDS}

students as partners, whole-of-institution approach, evaluation, challenges, shifts in perception, project management

Students as Partners (SaP) has become a hot topic in higher education, with increasing uptake by universities around the world (Matthews, Dwyer, Hine, \& Turner, 2018). SaP is a way of thinking and doing that re-positions students and staff as active and equal collaborators in a reciprocal process to enhance teaching and learning; curricula and pedagogy; and to engage in research (Cook-Sather, Bovill, \& Felten, 2014; Healey, Flint, \& Harrington, 2014). Praxis is central to enacting genuine $\mathrm{SaP}$, and is a commitment to the embodiment of certain principles and dispositions embedded within the critical pedagogy of SaP. These principles include fostering inclusivity; power sharing via dialogue and reflection; understanding partnership as a process with no certain outcomes; engaging ethically; and undertaking partnership for transformation (Dwyer, 2018; Matthews, 2017). Further, genuine SaP is thought to emerge from the social space established by the ongoing processes brought about by the embodiment 
of these principles and is therefore something more than just individual praxis (Dwyer, 2018; Matthews, Dwyer, Russell, \& Enright, in press).

Partnership is enacted across diverse settings; in small to large groups; in courses or across entire programs (Mercer-Mapstone et al., 2017); or at the institutional level, with a focus on university governance, strategy, or policy (Bovill, 2017; Shaw, Rueckert, Smith, Tredinnick, \& Lee, 2017). It is at this latter level-the implementation of university strategy-that this project is focused.

The University of Queensland (UQ) recently introduced SaP as one of the core goals of its Student Strategy 2016-2020, which aims to enhance the students' learning experience, and is planning how to implement the strategy in the coming years. In the latter half of 2017, the Students as Partners Program Design Project was initiated. This project took a collaborative approach to designing the UQ-wide SaP program by trialling different approaches. For each of the 11 SaP pilots, students and staff, with the support of the Student Strategy Team (SST), worked in partnership to contribute to one aspect of the overall program design (to inform university-wide implementation from 2018). Table 1 provides information about the pilot projects.

Table 1. 11 Pilot projects by title

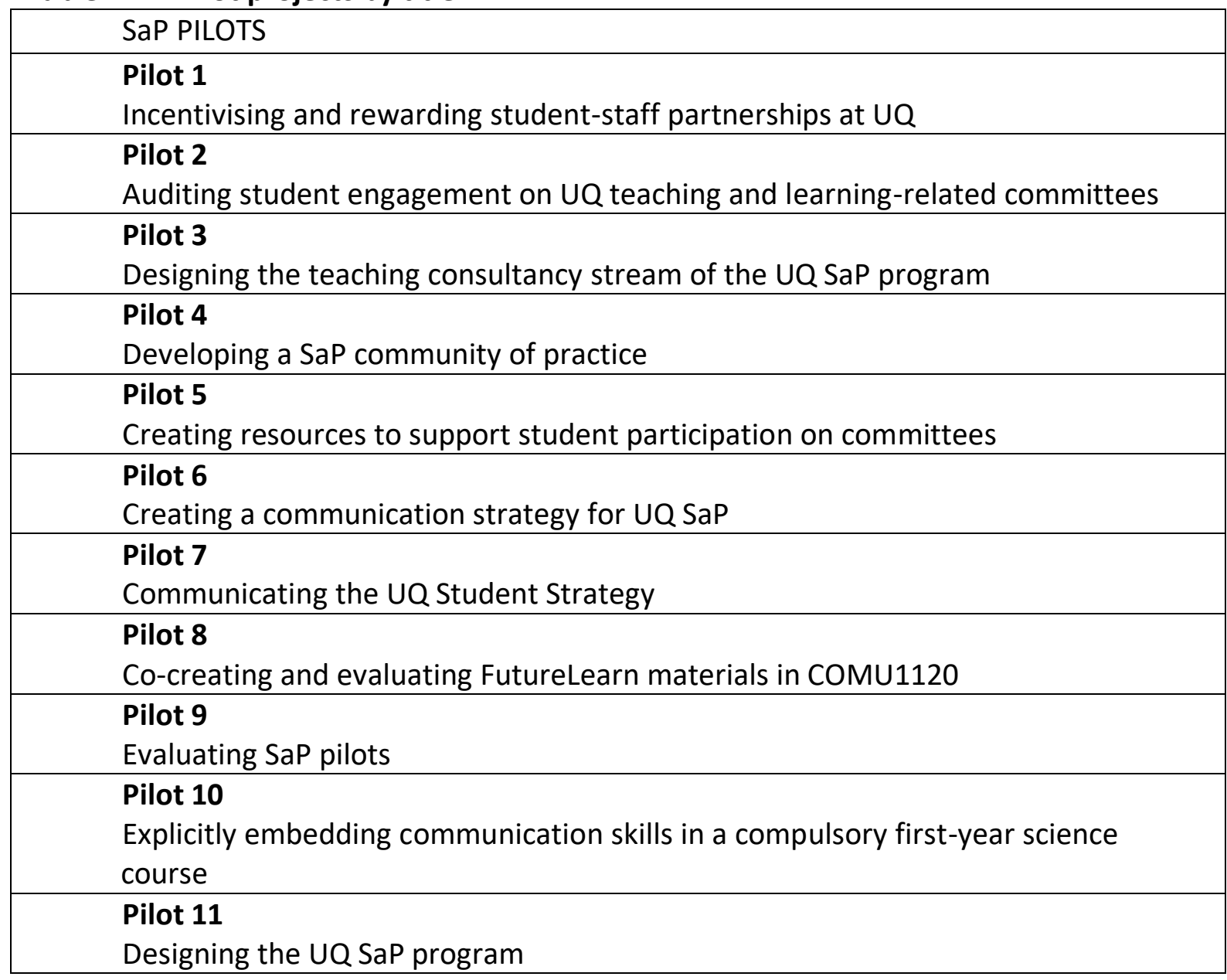

Coombe, L., Huang, J., Russell, S., Sheppard, K., \& Khosravi, H. (2018) Students as Partners in action: 86 Evaluating a university-wide initiative. International Journal for Students as Partners, 2(2). 
Overall, 29 students and 22 staff, in teams of two to 10 members, were engaged to work together as partners across these projects (The Institute for Teaching and Learning Innovation, 2017). The SST was responsible for recruiting participants. Staff members were nominated according to identified project needs or areas of expertise. Although there was no fixed time commitment, they were required to meet regularly with their project team and actively contribute to achieving the project's goals. Students were expected to spend either 50 or 100 hours on their project and received a stipend midway and at the end-similar to the SaP programs at McMaster University (Ahmad et al., 2017) and the University of Winchester (Lowe, Shaw, Sims, King, \& Paddison, 2017).

This case study (Pilot 9) was designed to evaluate the overall project with the intention of informing future implementation. The positioning of this study as an internal evaluation mechanism was considered challenging from the beginning (Volkov \& Baron, 2011). Consequently, during the formative stage, we were careful to ensure our role was independent from the SST. To achieve this independence, a staff member from the SST, who was assigned to the evaluation team, was asked to withdraw to avoid the conflict of interest that the rest of the team members had identified. This process required a robust conversation in the early days of the pilot, a process that effectively united the team from the beginning and helped to establish a trusting and respectful relationship.

\section{OUR APPROACH}

In a review of the literature on SaP evaluations, we noted predominantly positive outcomes reported for both students and staff. Furthermore, a recent systematic review summarising the benefits and challenges outlined in the existing literature (Mercer-Mapstone et al., 2017) noted that the challenges appeared to be under-reported, with up to $75 \%$ of the papers reviewed neglecting to report any challenges. Of those that did, the most prevalent was a reinforcement of pre-existing power inequalities, which inhibited a sense of trust between students and staff. Such outcomes are important to address: a failure to adequately clarify new and unfamiliar roles can impede input and collaboration (Bovill, Cook-Sather, Felten, Millard, \& Moore-Cherry, 2016). Other barriers include institutional structures and cultures, and promoting inclusivity for already marginalised students (Dwyer, 2018). It is unclear if these are common outcomes due to the under-reporting. This evaluation therefore sought to redress this by exploring both benefits and challenges experienced by staff and students throughout the pilots at UQ.

We also made an empirical observation of a cognitive shift that has been consistently alluded to in SaP practice due to its transformative nature (Curran, 2017; Marquis et al., 2015), also described as a threshold concept (Cook-Sather, 2014). A novel aspect of this evaluation was the pre-post survey design, developed to explore whether participants' perceptions of partnership change over the course of the pilots to reflect this shift (Berger, Kerner, \& Lee, 1999), and testing potential influencing factors. While the Pilot 9 evaluation was tasked with reporting on other facets of the overall program, this case study focuses on these two aspects. 


\section{RESULTS}

We designed and conducted two surveys. The first was administered at the mid-project point, the second in the final weeks of the project. Table 2 summarises response rates.

Table 2. Participant response rates

\begin{tabular}{|l|l|}
\hline PILOT PARTICIPANTS $(\mathrm{n}=51)$ & RESPONDENTS \\
\hline Survey 1 & $24(47 \%)$ \\
\hline Survey 2 & $19(37 \%)$ \\
\hline Both surveys & $13(25.5 \%)$ \\
\hline Gender & $75 \%$ female respondents \\
\hline Survey 1 only or both & $\begin{array}{l}13(54 \%) \text { students } \\
14(58.3 \%) \text { staff } \\
1 \text { in both student and staff category }\end{array}$ \\
\hline
\end{tabular}

\section{Benefits}

The benefits described by participants in this study closely reflected those already described elsewhere in the literature (Mercer-Mapstone et al., 2017). For students, there was enhanced motivation, ownership, and meta-cognitive awareness about their own learning, along with deepened understanding of, and contributions to, the academic community. Staff members, meanwhile, reported enhanced relationships with students and transformed ways of thinking about learning and teaching practices as a collaborative and ongoing process. Picking up on the theme of self-development and the increased meta-cognition described as benefits in the literature, we specifically asked respondents to indicate how their involvement in SaP activities enhanced this learning. Both students and staff noted the impact of face-toface communication, and the corresponding links between valuing diversity and developing emotional intelligence, in enabling them to work together effectively, as illustrated by the following quotation:

The fundamental change in my learning processes has been my consideration of issues from different perspectives. Having worked with people across all the faculties for a few weeks now, their differing approaches to problem solving have forced me to consider issues from a variety of perspectives in my own studies and, more broadly, my own life.

In terms of specific skill development, participants reported increased efficacy in multiple areas aside from research and pedagogical-related skills. These included multidisciplinary teamwork, leadership, communication, and interpersonal skills; project, enterprise, and evaluation skills; stress, time and self-management skills; and the use of various new technologies. 


\section{Challenges}

The most common challenge experienced by participants in the UQ pilots was time management (76\%), compared with communication (15\%), managing power imbalances and dominant personalities (5\%), and overcoming differences in experience and expertise within the teams (5\%). The insufficient allocation of time for the projects impacted participants' satisfaction with the pilots and their ability to develop relationships, a sense of belonging, and commit time to the pilot. Most respondents indicated they required either additional time or additional team members to effectively manage and complete the projects. One participant commented:

The major challenge for me has, unsurprisingly, been time. Current systems and policies afford very little recognition/acknowledgement of the value of this kind of work and it takes longer to develop meaningful partnerships than it does to tell students exactly what to do, what to be interested in, and how to do whatever it is that needs doing.

For staff, respondents indicated that this may be alleviated if the time spent on SaP projects was recognised as constituting part of their professional workloads. For students, the most reported time management issue was balancing study loads with project requirements. Assistance for students in balancing workloads may alleviate this barrier. Alternatively, undertaking less ambitious and time-consuming projects, or extending them beyond single semester time frames, would naturally reduce this challenge, as has been recently recognised elsewhere (Ahmad et al., 2017; Marie \& McGowan, 2017).

The initial challenge of time frames was increased when project teams were unsure of what their project was expected to achieve, and requested more guidance from the SST. This added pressure as teams typically needed to spend more time developing concrete goals and forming authentic relationships (Dwyer, 2018). Typical recommendations from respondents included more clearly expressed and detailed output expectations; reflections on lived experience during induction; more distinct submission deadlines (reporting); and communicating more realistically the level of commitment necessary in advertising for partners.

Exacerbating the time frame issues was the number of additional outputs, which accumulated throughout the semester, in addition to specific project outputs. Reports and reflections on the process for each pilot, required by the SST, as well as requests for contributions being generated from other pilots, was a workload that most found difficult to effectively manage.

The overwhelming focus on time as the key challenge by participants was likely to be a consequence of the wide-scale implementation and pilot nature of the projects and the need to inform UQ-wide program development. Nevertheless, the need to reduce the total output requirements and limit bureaucratisation for future projects was a clear learning from this process.

\section{Perception shift}

Given $75 \%$ of participants in the pilots had not previously engaged in SaP activities, they were asked to indicate how they perceived their confidence and ability to do so effectively at 
different stages of the project life cycle on a Likert Scale of 1 to 4 . As shown in Figure 1, participants felt increasingly more confident with their own capacity to contribute over the course of the semester.

\section{Figure 1: Ability to contribute to SaP}

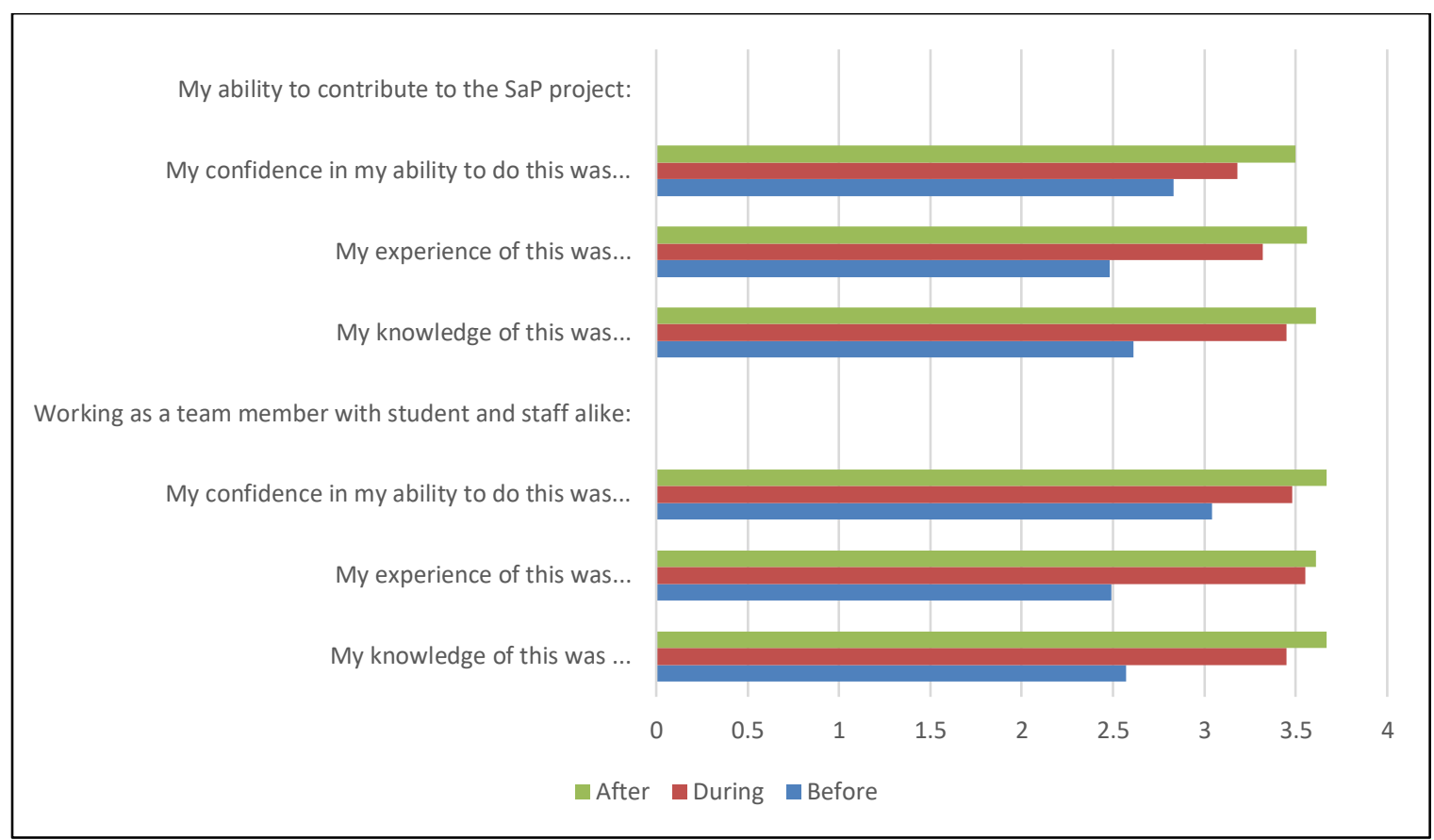

When asked how their preconceived expectations of SaP had changed, the key themes that emerged indicated that it was an enactment of the values of partnership, as outlined by Healey et al. (2014) that created this shift. Responses reflected the values of authenticity, inclusivity, reciprocity, empowerment, trust, challenge, community, and responsibility, suggesting these values could be used as a framework to structure future surveys.

Participants were similarly asked to rate their experience of working in partnership during and after completion of their projects. Measures used related to a sense of empowerment, trust/respect, and engagement/involvement. While the average response was positive in all measures, with most participants agreeing that their experience was positive, there was again an improvement over the life cycle of the projects (Figure 2). In the final survey, all participants were satisfied with their overall experience, with an average rating of 3.58 out of 4 achieved. 


\section{Figure 2: Positive experiences of working in partnership}

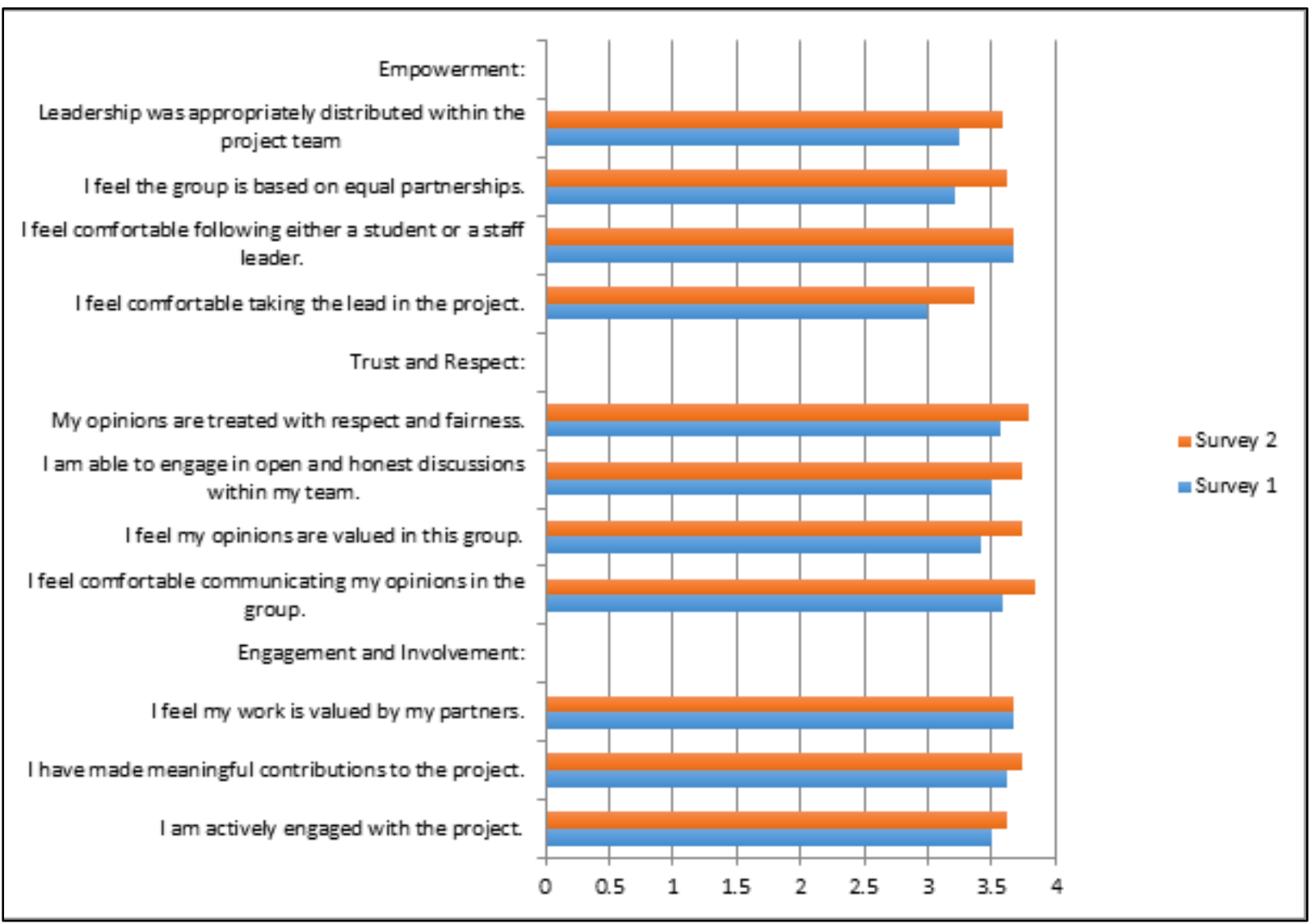

A limited number of participants noted that instead of an authentic partnership, the dynamic in their teams was based more on an expert-assistant dynamic, as has been noted elsewhere, with staff retaining the power and students unwilling to challenge their authority (Ahmad et al., 2017; Kehler, Verwoord, \& Smith, 2017; Lowe et al., 2017; Mercer-Mapstone et al., 2017). However, these comments were mainly in response to the first survey and were attributed to the focus being on the end-product and what the academic needed done, rather than on the process of working in partnership. While this sentiment of power imbalance was echoed in the feedback from the second survey, overall it was much more positive than the first, with participants commenting on the increasing socialisation aspects of their projects and pride in the quality of their project outcomes-again reflecting a direct attribution to the values of partnership for the shift in perceptions. The implication of this finding for professional development requirements for $\mathrm{SaP}$ is the need to highlight a life cycle approach that focuses on relational values.

Allied with this understanding was the need to establish an actual program titled Students as Partners to act as a centralised space from which to establish, recruit, and coordinate future SaP projects. Respondents envisaged this program to be linked with mentoring and other support programs, resources, and services-and thus the broader UQ community -in much the same way as described by Shaw et al. (2017). In general, respondents 
wanted greater project integration, including mandatory communication and meetings between pilots of a similar type, or associated within the same discipline or faculty. This was linked to the desire for participation in a community of practice in several responses. Although respondents typically see this as a whole-of-institution program, they also commented on the need to pave the way for projects within the faculties to increase awareness of SaP. Respondents see SaP as procedural rather than outcome-oriented and, most importantly, embodying the ethos of partnership. Respondents typically produced this vision in association with ways to effectively up-scale the SaP program.

\section{RECOMMENDATIONS}

Based on the evidence presented in this case study, the following recommendations are made for future implementation of SaP in large higher education institutions:

1. Allow sufficient time for teams to form as a partnership prior to commencing work on project outputs.

2. Allow sufficient time frames and resourcing for projects.

3. Include out-of-semester time for projects to facilitate increased student participation.

4. Make time commitments and project expectations explicit at time of advertising projects.

5. Communicate better with schools and faculties involved in projects regarding expectations.

6. Consider a life cycle approach to project implementation and professional development.

\section{CONCLUSIONS}

This case study, in itself a SaP project, evaluated a series of pilot projects to inform the strategic directions for scaling up SaP as a whole-of-institution program. A key challenge for participants was the short time frame available to develop genuine partnerships and achieve multiple required outputs. This overshadowed commonly experienced power imbalances described elsewhere (Mercer-Mapstone et al., 2017), potentially explained by both the pilot nature and involvement of predominantly experienced staff in SaP projects. Challenges associated with the practical components of embedding SaP within a whole-of-institution program included adequate central support systems, clear project expectations, and incentive schemes that meet the needs of both staff and students.

Another finding was the measurable shift in perceptions of participants regarding their efficacy to participate in SaP initiatives. Our results suggest a direct correlation with the enactment of values of partnership, as outlined by Healey et al. (2014), which warrants further research.

We received approval from our Human Research Ethics Committee (\#2017001378) for our study. 


\section{NOTE ON CONTRIBUTORS}

Leanne Coombe is the Academic Lead for Curriculum Support and Innovation for the Faculty of Medicine at The University of Queensland. Her research over the last five years, which draws on mixed-methods but prioritises qualitative approaches, has involved leading a national research team as principal investigator, focusing on models of curriculum integration of Indigenous health competencies.

Jasmine Huang is completing her BA Honours in psychology and has experience in applying both qualitative and quantitative approaches. Her previous projects involve developing evaluation tools for the Boeing Livewell Collaborative Studio in researching the needs of middle-aged passengers, data analysis, and delivering prototypes that have been patented.

Stuart Russell is a final-year undergraduate student undertaking an extended major in anthropology. He brings experience working in interdisciplinary student-staff partnerships analysing qualitative data around academic leaders' conceptions of SaP. Stuart has also completed research using ethnographic and mixed-method approaches in both urban and remote settings.

Karen Sheppard has worked on a number of large-scale national research projects investigating the contemporary Bachelor of Arts degree program. She has been responsible for the participant recruitment, obtaining consent, data collection, and data analysis as well as the evaluation of the quality of research at The University of Queensland.

Hassan Khosravi undertakes research into personalising education and translating traditional on-campus learning into authentic flexible learning in vibrant digital environments that better suit the needs and expectations of a digitally minded generation. He employs exemplary techniques to design, implement, validate, and deliver solutions that use the digital footprints of learners.

\section{REFERENCES}

Ahmad, A., Ali, A., VanMaaren, J., Barrington, J., Merritt, O., \& Ansilio, K. (2017). Partnership in practice: Implementing Healey's conceptual model. International Journal for Students as Partners, 1(2). https://doi.org/10.15173/ijsap.v1i2.3197

Berger, C., Kerner, N., \& Lee, Y. (1999). Understanding student perceptions of collaboration, laboratory and inquiry use in introductory chemistry. National Association for Research in Science Teaching.

Bovill, C. (2017). A framework to explore roles within student-staff partnerships in higher education: Which students are partners, when, and in what ways? International Journal for Students as Partners, 1(1), https://doi.org/10.15173/ijsap.v1i1.3062

Bovill, C., Cook-Sather, A., Felten, P., Millard, L., \& Moore-Cherry, N. (2016). Addressing potential challenges in co-creating learning and teaching: Overcoming resistance, 
navigating institutional norms and ensuring inclusivity in student-staff partnerships. Higher Education: The International Journal of Higher Education Research, 71(2), 195-208.

Cook-Sather, A. (2014). Student-Faculty partnership in explorations of pedagogical practice: A threshold concept in academic development. International Journal for Academic Development, 19(3), 186-198.

Cook-Sather, A., Bovill, C., \& Felten, P. (2014). Engaging students as partners in teaching and learning: A guide for faculty. San Francisco, CA: Jossey-Bass.

Curran, R. (2017). Students as Partners-good for students, good for staff: A study on the impact of partnership working and how this translates to improved student-staff engagement. International Journal for Students as Partners, 1(2). https://doi.org/10.15173/ijsap.v1i2.3089

Dwyer, A. (2018). Toward the formation of genuine partnership spaces. International Journal for Students as Partners, 2(1), https://doi.org/10.15173/ijsap.v2i1.3503

Healey, M., Flint, A., \& Harrington, K. (2014). Engagement through partnership: Students as partners in learning and teaching in higher education. York: Higher Education Academy. Retrieved from https://www.heacademy.ac.uk/system/files/resources/engagement through partnershi p.pdf

Kehler, A., Verwoord, R., \& Smith, H. (2017). We are the process: Reflections on the underestimation of power in students as partners in practice. International Journal for Students as Partners, 1(1). https://doi.org/10.15173/ijsap.v1i1.3176

Lowe, T., Shaw, C., Sims, S., King, S., \& Paddison, A. (2017). The development of contemporary student engagement practices at the University of Winchester and Winchester Student Union, UK. International Journal for Students as Partners, 1(1). https://doi.org/10.15173/ijsap.v1i1.3082

Marie, J., \& McGowan, S. (2017). Moving towards sustainable outcomes in student partnerships: Partnership values in the pilot year. International Journal for Students as Partners, 1(2). https://doi.org/10.15173/ijsap.v1i2.3081

Marquis, E., Puri, V., Wan, S., Ahmad, A., Goff, L., Knorr, K., Vassileve, I., \& Woo, J. (2015). Navigating the threshold of student-staff partnerships: A case study from an Ontario teaching and learning institute. International Journal for Academic Development, 21(1), 415.

Matthews, K. E. (2017). Five propositions for genuine students as partners practice. International Journal for Students as Partners, 1(2), https://doi.org/10.15173/ijsap.v1i2.3315

Matthews, K. E., Dwyer, A., Hine, L., \& Turner, J. (2018). Conceptions of students as partners. Higher Education, 1-15.

Matthews, K.E., Dwyer, A., Russell, S., \& Enright, E. (2018) It is a complicated thing: leaders' conceptions of students as partners in the neoliberal university. Studies in Higher Education. https://doi.org/10.1080/03075079.2018.1482268

Mercer-Mapstone, L., Dvorakova, S. L., Matthews, K. E., Abbot, S., Cheng, B., Felten, P., \& Swaim, K. (2017). A systematic literature review of students as partners in higher 
education. International Journal for Students as Partners, 1(1).

https://doi.org/10.15173/ijsap.v1i1.3119

Shaw, N., Rueckert, C., Smith, J., Tredinnick, J., \& Lee, M. (2017). Students as Partners in the real world-a whole-institution approach. International Journal for Students as Partners, 1(1). https://doi.org/10.15173/ijsap.v1i1.3079

The Institute for Teaching and Learning Innovation. (2017). Students as Partners projects at UQ. Retrieved from http://itali.uq.edu.au/content/uq-pilot-projects

Volkov, B., \& Baron, M. (2011). Issues in internal evaluation: Implications for practice, training, and research. New Directions for Evaluation, 132, 101-111. 